\title{
A importância da Perfilagem Sísmica Contínua na hidrografia portuária
}

\author{
Luiz Antonio Pereira de Souza - IPT
}

Copyright 2021, SBGf - Sociedade Brasileira de Geofísica.

This paper was prepared for presentation during the $17^{\text {th }}$ International Congress of the Brazilian Geophysical Society held in Rio de Janeiro, Brazil, 8-11 November 2021.

Contents of this paper were reviewed by the Technical Committee of the $17^{\text {th }}$ International Congress of the Brazilian Geophysical Society and do not necessarily represent any position of the SBGf, its officers or members. Electronic reproduction or storage of any part of this paper for commercial purposes without the written consent of the Brazilian Geophysical Society is prohibited.

\section{Resumo}

Levantamentos geofísicos em áreas portuárias visam sempre a segurança da navegação, e portanto, tem por objetivo dar suporte aos projetos de manutenção do calado adequado e estabelecido para cada porto. Neste contexto, é fundamental a obtenção de dados precisos relativos à espessura da coluna d'água, a presença de obstruções náuticas (fragmentos de embarcações, afloramentos rochosos etc.) e da espessura da coluna sedimentar. Para essas finalidades destacam-se, respectivamente, os métodos acústicos de Batimetria, Sonar de Varredura Lateral e Perfilagem Sísmica Contínua. Métodos Magnetométricos e Elétricos são também aplicados na investigação destes ambientes com essas finalidades.

A Perfilagem Sísmica Contínua tem um papel especial no processo de viabilização de projetos portuários, pois possibilita a caracterização da espessura da coluna sedimentar subsuperficial, subsidiando projetos de dragagem, que são fundamentais tendo em vista a dinâmica sedimentar destes ambientes.

Esta técnica tem evoluído nestas últimas décadas na direção de possibilitar aquisição simultânea de dados oriundos de distintos espectros de frequências, desde $500 \mathrm{~Hz}$ a $50000 \mathrm{~Hz}$, o que possibilita a integração em tempo real da abordagem deste tema sob o ponto de vista da resolução e da penetração. Mais recentemente, constata-se uma evolução tecnológica na direção da possibilidade de execução da Perfilagem Sísmica Contínua de varredura, método de extrema relevância também na inspeção subaquática. 